\title{
PURIFICATION AND COMPRESSION OF BIOGAS: A RESEARCH EXPERIENCE
}

\author{
Er.Tri Ratna Bajracharya, Ph.D. \\ Associate Professor, Mechanical Engineering Department, Pulchowk Campus, Institute of Engineering, Tribhuvan \\ University \\ Corresponding Email Address: triratna@ioe.edu.np
}

Er. Alok Dhungana, Er. Nirajan Thapaliya, Er. Gogan Hamal

Research Associate, Department of Mechanical Engineering, Pulchowk Campus, Institute of Engineering, Tribhuvan University

\begin{abstract}
Biogas is widely used in villages of Nepal for cooking and lighting. But its commercial use has never been realized due to difficulties in its storage and transportation. Solution identified to the problem is to increase the energy density of the gas through removal of incombustible and corrosive gas and consequent compression which was experimented on a lab-scale model. This paper presents all the results of removal of $\mathrm{CO}_{2}$ gas from biogas using different chemicals and relative purity with raw gas. Further, compression of biogas and was carried out by methane refrigerant compressor and bottled into normal LPG cylinder. Compression of biogas was carried out under near Isothermal and Adiabatic conditions up to 11 bar absolute pressure. The energy efficiency of compression was determined to be $98.71 \%$ and if the gas used for generation of electricity using a generator with an efficiency of $30 \%$, the net energy efficiency turned out to be $95.72 \%$. Later, a boiling test was conducted whereby the combustibility of the compressed biogas from the cylinder in normal biogas-stove was tested to validate its use in cooking, the results of which are included.
\end{abstract}

Key words: Purification of Biogas, Compression of Biogas, Chemical purification, Energy efficiency, Combustion test.

\section{INTRODUCTION}

Biogas is a flammable mixture of different gases that is produced by decomposition of biodegradable organic matters by microorganisms in absence of air (or oxygen). Biogas is produced by anaerobic digestion of biological wastes such as cattle dung, vegetable wastes, sheep and poultry droppings, municipal solid waste, industrial wastewater, landfill, etc. Production of biogas involves a complex physiochemical and biological processes involving different factors and stages of change. Main products of the anaerobic digestion are biogas and slurry. Biogas is constituted of different component gases the majority of them being methane $\left(\mathrm{CH}_{4}\right)$ and Carbon dioxide $\left(\mathrm{CO}_{2}\right)$ with traces of Sulphur Dioxide $\left(\mathrm{H}_{2} \mathrm{~S}\right)$ and Hydrogen $\left(\mathrm{H}_{2}\right)$ gas. Composition of a typical biogas sample in Nepal is given in the table below:

Table 1 Composition of Biogas

\begin{tabular}{|l|l|l|}
\hline Substance & Symbol & Percentage \\
\hline Methane & $\mathrm{CH}_{4}$ & $50-70$ \\
\hline Carbon Dioxide & $\mathrm{CO}_{2}$ & $30-40$ \\
\hline Hydrogen & $\mathrm{H}_{2}$ & $5-10$ \\
\hline Nitrogen & $\mathrm{N}_{2}$ & $1-2$ \\
\hline Water Vapor & $\mathrm{H}_{2} \mathrm{O}$ & 0.3 \\
\hline $\begin{array}{l}\text { Hydrogen } \\
\text { Sulphide }\end{array}$ & $\mathrm{H}_{2} \mathrm{~S}$ & Traces \\
\hline
\end{tabular}

Source: [2] 
In the above table, we can see the combustible components of biogas are $\mathrm{CH}_{4}$ and $\mathrm{H}_{2}$. Other gases are not flammable at normal conditions and have no energy contribution in biogas. Also, among these two gases only $\mathrm{CH}_{4}$ is present in a significant amount and hence, is considered in most cases involving biogas.

In Nepal, major application of biogas has only been in cooking and lighting. Commonly the gas produced in the digester is transported to desired place say kitchen by pipe line, on the pressure developed in the digester dome itself. But this is not sufficient to transport gas to farther distances from the generation site. This is why, uses of biogas are crippled. Moreover, due to its limited use biogas until now is not produced at a convincing amount. A large scale biogas plant producing a large amount of biogas is often rendered worthless due to the lack of its effective and efficient use. Due to this lack of portability of biogas there have been no efforts whatsoever to commercialize the use of biogas.

The main problems associated with the commercialization with biogas are:

- Its low energy content per unit volume.

- It is difficult to liquefy.

- It is not produced in large amount at a same place.

For the commercialization of the biogas, it is important to make it portable and compatible for various commercial purposes. For that, the energy content for a particular volume must also be increased. This requires compression of the gas to as higher pressures as possible. Storage of the gas is another concern as the cylinder becomes heavy and bulky for higher pressures. This will increase the weight of the cylinder and hence, affect its portability. Hence, other means of increasing the energy content is to purify the gas, i.e. to remove incombustible gas present in biogas.

\section{MATERIALS AND METHODOLOGY OF THE STUDY}

The study was carried out on lab scale models. This topic was never studied before in Nepal hence experiments were performed from basic level and improvements were made through trial and error. Due to unavailability of standard instruments required to verify the results, experiments were limited as a preliminary study and a very important guide to next level of research.

Below, different streams of experiment, their theories, procedures and design are explained accordingly.

\subsection{Purification}

In purification, it is intended to enrich the methane content in the biogas. Primary option was to use pressurized water scrubber, which was suitable both from technical and economic point of view in Nepal at commercial scale. Other processes like pressure swing absorber, membrane separation, activated carbon sieve method, cryogenic etc. were either too expensive or technically infeasible. Due to lack of fund to install the setup, an alternative method for $\mathrm{CO}_{2}$ removal using suitable chemicals (alkalis) was considered for the study of purification and its subsequent compression. The chemicals used were Calcium Oxide $(\mathrm{CaO})$, Calcium Hydroxide $\left(\mathrm{Ca}(\mathrm{OH})_{2}\right)$ and Ammonium Hydroxide $\left(\mathrm{NH}_{4} \mathrm{OH}\right)$.

\subsubsection{Chemical purification Theory}

$\mathrm{CO}_{2}$ is an acidic gas; it forms Carbonic Acid $\left(\mathrm{H}_{2} \mathrm{CO}_{3}\right)$ upon dissolving in water. Hence, for the absorption of $\mathrm{CO}_{2}$ gas suitable bases have to be used to result an acid-base neutralization reaction thereby, absorbing and reducing the $\mathrm{CO}_{2}$ content in biogas. 


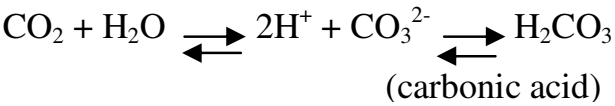

The chemicals used were Calcium Oxide $(\mathrm{CaO})$, Calcium Hydroxide $\left(\mathrm{Ca}(\mathrm{OH})_{2}\right)$ and Ammonium Hydroxide $\left(\mathrm{NH}_{4} \mathrm{OH}\right)$. Chemicals were changed due to unsatisfactory results obtained from the experiments. That's why we also changed $\mathrm{CaO}$ to $\mathrm{Ca}(\mathrm{OH})_{2}$ to obtain positive results. Basic chemical reactions to absorb $\mathrm{CO}_{2}$ are mentioned below:

$\mathrm{CaO}+\mathrm{H}_{2} \mathrm{CO}_{3} \longrightarrow \mathrm{CaCO}_{3}+\mathrm{H}_{2} \mathrm{O}$

$$
\begin{aligned}
& \mathrm{Ca}(\mathrm{OH})_{2}+\mathrm{H}_{2} \mathrm{CO}_{3} \rightarrow \mathrm{CaCO}_{3}+\mathrm{H}_{2} \mathrm{O} \\
& \mathrm{NH}_{4} \mathrm{OH}+\mathrm{H}_{2} \mathrm{CO}_{3} \rightarrow \mathrm{NH}_{4} \mathrm{HCO}_{3}+\mathrm{H}_{2} \mathrm{O} \\
& 2 \mathrm{NH}_{4} \mathrm{OH}+\mathrm{H}_{2} \mathrm{CO}_{3} \rightarrow\left(\mathrm{NH}_{4}\right)_{2} \mathrm{CO}_{3}+2 \mathrm{H}_{2} \mathrm{O}
\end{aligned}
$$

\section{Regeneration theory}

Regeneration of the spent chemical becomes very important if we are going to commercially use the chemical for the purification process. $\mathrm{CaCO}_{3}$ is the product of both $\mathrm{CaO}$ and $\mathrm{Ca}(\mathrm{OH})_{2}$. Its when heated to
$825{ }^{\circ} \mathrm{C}$ dissociates back to Calcium Oxide and Carbon Dioxide. This is how Calcium Oxide is manufactured from limestone (Calcium Carbonate). But this requires very high temperature and long process rendering it inappropriate for its economical use.

But ammonia can be easily regenerated by heating ammonia carbonates and bicarbonates to $60-80{ }^{\circ} \mathrm{C}$ for $5-10$ minutes[8]. Otherwise, these are used as chemical fertilizer, hence can be sold without regeneration.

\section{Chemical Purification setup and methodology:}

The purification setup was simple and suited for low flow-rate. We conducted our experiments at flow-rates roughly around 300lit/hour. For increasing the flow-rate, better gas diffusing methods and large volume of chemical must be used. Besides, stirrer is also required to ensure the proper diffusion of the unreacted chemical.

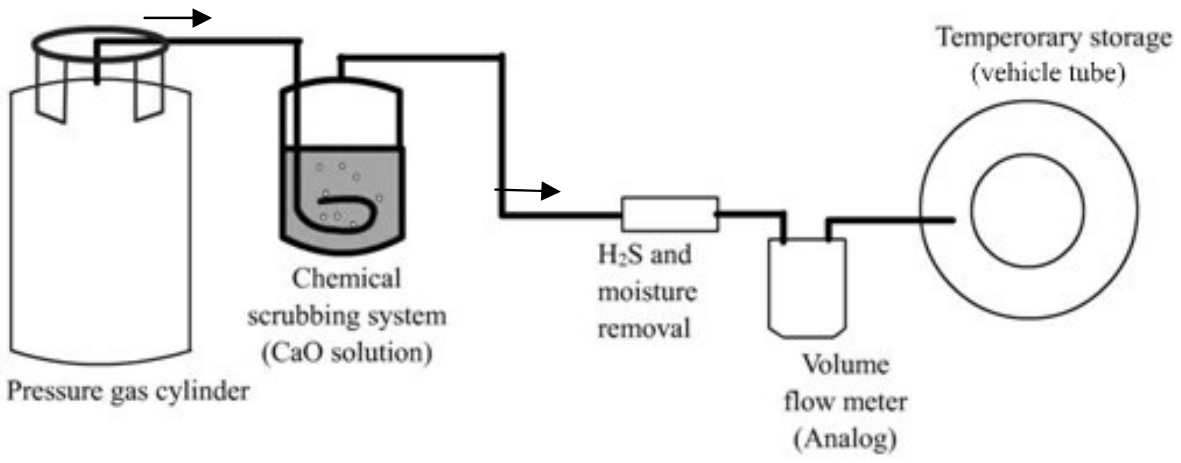

Figure 1 Chemical purification setup line diagram.

In figure 1, raw biogas is stored in pressurized form at around 5 bar in the pressure vessel, which is a 33 litres LPG cylinder. Then the gas is allowed to pass at low pressure around $10 \mathrm{kPa}$ through the chemical scrubbing system consisting alkali solution. Chemical scrubbing system is fabricated from a recycled 15 litres low pressure gas cylinder. The gas is bubbled from a perforated pipe dipped into the solution for proper mixing. Gas then passes from $\mathrm{H}_{2} \mathrm{~S}$ scrubber and moisture absorber. Flow of gas is measure from inline volume flow meter. Finally the purified gas is stored in a vehicle tube. Vehicle tube was chose for 
its advantage to be completely evacuated refilling with different tests gases.

The flow meter is specified to measure the flow of natural gas at a pressure of upto 10 $\mathrm{kPa}$ with a least count of 0.2 litres and can measure accurately for a flow of $0.0025 \mathrm{~m}^{3} / \mathrm{hr}$ to $4 \mathrm{~m}^{3} / \mathrm{hr}$. The pipes for the purification setup were 1/4" flexible pipes connected together using nipple, T-joint and metallic globe valves.

Apart from this setup for normal purification experiment an additional setup was also used with an ammonia entrapment mechanism as shown in figure 2 .

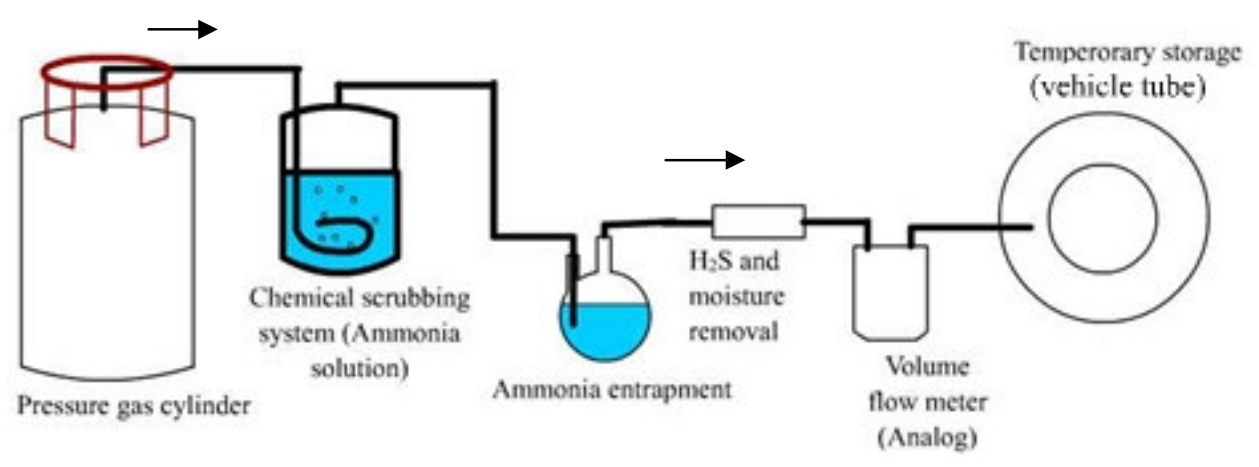

Figure 2 Line diagram for gas purification system using aqua ammonia.

This mechanism was used to restrict the diffusion of Ammonia into biogas from Ammonia solution. Utilizing the fact that ammonia has a very high affinity towards water compared to methane, a jar containing water was taken and the outlet gas from the chemical container passed through water as shown in the figure below. Water would then absorb ammonia from biogas.

Furthermore to validate the regeneration of the aqua ammonia, another setup as shown in figure 3 was designed. Where the same chemical scrubbing system or the low pressure cylinder is heated and the gas coming out is passed through ammonia entrapment, and remaining $\mathrm{CO}_{2}$ is allowed to escape in atmosphere. The solution was heated for 10 minutes maintaining $80^{\circ} \mathrm{C}$ temperature.

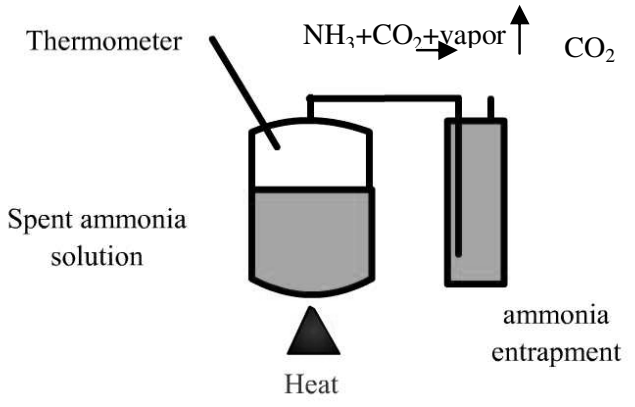

Figure 3 Ammonia regeneration setup line diagram

To identify if we have regenerated chemical or not, we had no other option than to use it in boiling test under similar condition and compare the value.

\section{Gas purity testing}

Due to unavailability of gas analyser, calorific value of raw biogas and purified biogas were compared. Since, only $\mathrm{CH}_{4}$ and not $\mathrm{CO}_{2}$ contributes to the calorific value, there exists a direct relation between the volume of $\mathrm{CH}_{4}$ present in a given volume of biogas and the corresponding calorific value of the given biogas. Hence we can 
approximately identify percentage $\mathrm{CH}_{4}$ in purified gas, assuming an initial standard composition of raw biogas $\left(60 \% \mathrm{CH}_{4}\right.$ and $40 \% \mathrm{CO}_{2}$ in our case). The calorific value of raw biogas measured should not be confused with the standard value, as our value is obtained in our laboratory condition.

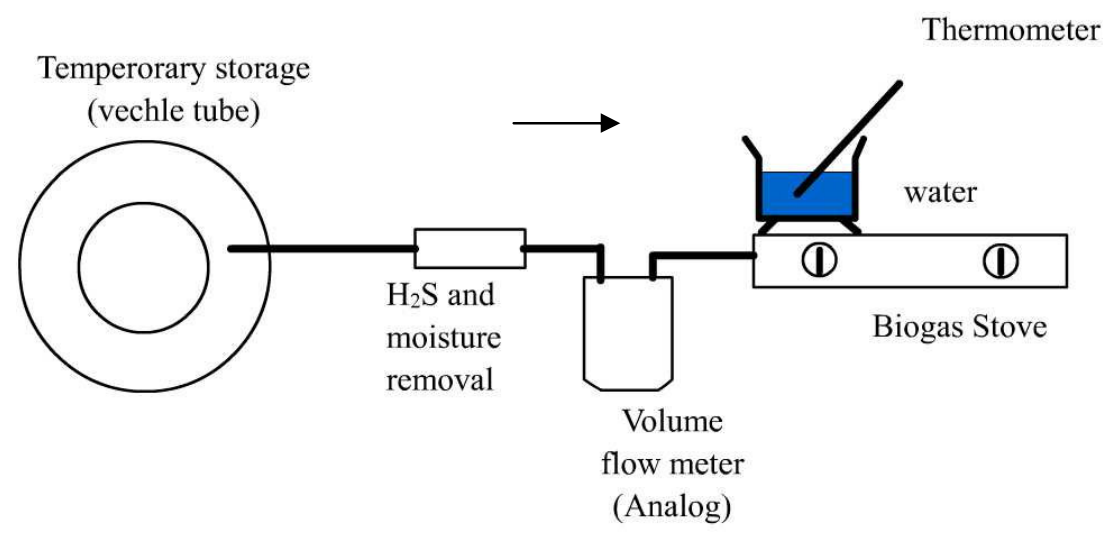

Figure 4 Setup for testing calorific value of biogas

Referring from figure 1 and 2, purified gas was stored in the vehicle tube, which is now used in this setup in figure 4 . This gas is then used to boil specified volume of water for specified minutes. Similar condition of this test with raw and purified gas is repeated to determine the relative purity of the gas.

\section{Compression and Storage}

Methane is an inflammable gas. A common gas compressor posses fire hazards, since auto-ignition temperature of biogas is 537 ${ }^{\circ} \mathrm{C}$. So leakage and excessive temperature rise will be fatal. Hence we used a hermetic reciprocating compressor used in a refrigeration system with a hydrocarbon refrigerant. It requires cooling system, otherwise careful operation must be done so as not to raise the temperature above safe limits.

Compression was carried out maintaining near isothermal and near adiabatic conditions. In Near isothermal condition the temperature of the gas was tried to keep constant with intermittent compression, but in adiabatic compression the heat loss was tried to minimize with continuous compression. The pressure and volume of the gas at various points of compression can be noted using a pressure gauge and flow-meter respectively.

For storing gas after compression, a LPG cylinder was used. LPG cylinders have a volumetric capacity of 33 litres and a net weight of $15.4 \mathrm{Kg}$. LPG exerts a pressure of 5-7 bars while stored in the cylinder. However, they are designed for a pressure of 25.3 bars. [Source: Nepal Standards]

\subsubsection{Compression setup:}

The compression setup consists primarily of a hermetic reciprocating type hydrocarbon refrigerant compressor as discussed above and shown in the figure below. The inlet pipe to the compressor was a $1 / 4$ " flexible hose and the outlet was $1 / 4$ " copper tube. The delivery piping consisted of a one-way valve, a t-joint leading to a pressure gauge (maximum pressure 30 bars and accuracy of 0.5 bars) and a high pressure flexible pipe connecting to regulator on the LPG cylinder, where the pressurized gas is stored. 


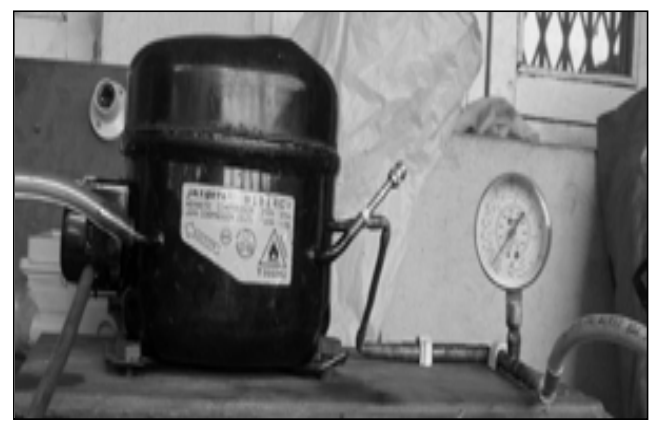

Figure 5 Compression system setup

\section{Stove compatibility test}

After the compression of biogas into the cylinder, we needed to verify its compatibility with cookers and its efficiency. Here, the gas stored in the LPG cylinder in compressed form at 11 bar was tested on LPG and Puxin biogas stove. The volume of biogas burnt was measured using the analog flow-meter and the temperature of water measured at regular intervals. Excessive pressure from the cylinder was controlled by the regulator.

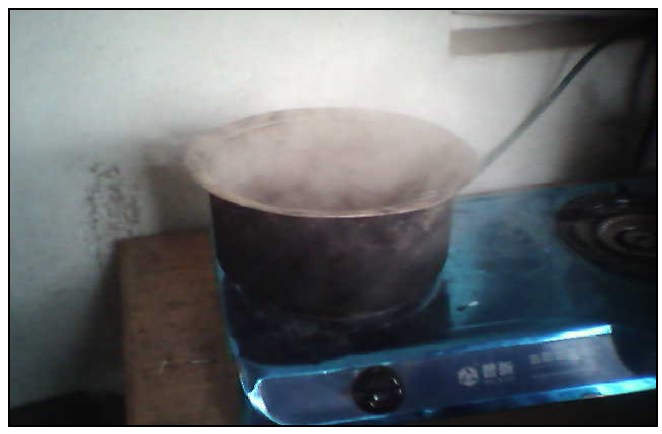

Figure 6 Boiling of water using Compressed Biogas

\section{RESULTS AND DISCUSSIONS}

\section{Purification}

As explained earlier purification of the gas was done using different chemicals and relative purity of the gas was tested by boiling tests, results of which are listed below:

\begin{tabular}{|l|l|l|l|l|l|l|}
\hline S.N & $\begin{array}{l}\text { Chemica } \\
1\end{array}$ & $\begin{array}{l}\text { Volume } \\
\text { of raw gas } \\
\text { used for } \\
\text { chemical } \\
\text { purificatio } \\
\mathrm{n} \text { (litres) }\end{array}$ & $\begin{array}{l}\text { Calorif } \\
\text { ic } \\
\text { Value } \\
\text { of raw } \\
\text { biogas } \\
\text { (MJ/m } \\
3 \text { ) }\end{array}$ & $\begin{array}{l}\text { Volume } \\
\text { of gas } \\
\text { after } \\
\text { chemic } \\
\text { al } \\
\text { reaction }\end{array}$ & $\begin{array}{l}\text { Calorif } \\
\text { ic } \\
\text { Value } \\
\text { of } \\
\text { purifie } \\
\text { d } \\
\text { biogas } \\
\text { (MJ/m } \mathrm{m}^{3} \\
\text { ) }\end{array}$ & $\begin{array}{l}\text { Remar } \\
\mathrm{k}\end{array}$ \\
\hline 1. & $\begin{array}{l}\text { Calcium } \\
\text { Oxide } \\
\text { (lab } \\
\text { grade) }\end{array}$ & - & 6.84 & - & 3.95 & $\begin{array}{l}\text { Negati } \\
\text { ve } \\
\text { result }\end{array}$ \\
\hline 2. & $\begin{array}{l}\text { Calcium } \\
\text { Hydroxi } \\
\text { de }\end{array}$ & 32 & 6.84 & 22 & 5.5 & $\begin{array}{l}\text { Negati } \\
\text { ve } \\
\text { result }\end{array}$ \\
\hline 3. & $\begin{array}{l}\text { Aqua } \\
\text { Ammoni } \\
\text { a }\end{array}$ & 25 & 6.84 & 19.8 & 4.88 & $\begin{array}{l}\text { Negati } \\
\text { ve } \\
\text { result }\end{array}$ \\
\hline
\end{tabular}

*(This value is much less than the practical value for biogas pertaining to the heat losses to the atmosphere and inefficiencies of stove in burning the gas)

The results show that though there is a reduction in volume of biogas upon passing through the chemical indicating absorption of a gas (theoretically $\mathrm{CO}_{2}$ ), the calorific value observations show quite disappointing results as there is a decrease in the calorific value of chemically treated gas than that of raw biogas. The reasons identified are:

- Since the lab setup was a batch type system, the best was tried to stop inclusion of air or other gases into the system during the intermittent period. Our choice of vehicle tube accounts for the remedy. But on analysis it was found that a blunder that our chemical purification tank of 12 litres had a free space of 3-5 litres. While disconnecting the temporary storage and reconnecting it after another set of test, we must have infiltrated air. And our testing was done with only 20-30litres of gas; hence the infiltration had bigger effect. 
- Other reasons possibly that the gases such as ammonia get into the main stream or methane itself might also have been absorbed by the chemical.

A particular reason for the loss could not be identified due to the lack of proper measuring instrument to measure the composition of the gas.

\section{Regeneration of aqua ammonia}

After bubbling biogas through aquaammonia solution, crystals of ammonium carbonate and ammonium bio-carbonate were visible on the orifice of the flexible pipe dipped into the solution. Then to regenerate this spent solution again, we heated the solution as explained in the methodology and again passed raw gas through the regenerated solution in same quantity and almost same flow-rate. The quality of regenerated solution was tested by testing the calorific value of the purified gas. It again showed negative value due to the probable reasons already explained.

\section{Compression and Storage}

\section{Near Isothermal}

This condition was developed trying to achieve constant temperature inside the cylinder. We stopped for few minutes after each bar to cool down the gas and the compressor. But still, at higher pressure, gas would heat up at high pace. Hence, it is not ideally isothermal condition.

The graph shown below is developed by taking reading from pressure gauge and the flow-meter, which shows atmospheric volume of gas which is stored inside the cylinder with increase in pressure.

During isothermal compression we could store a total of 443 litres of biogas in the 33 litre LPG cylinder.

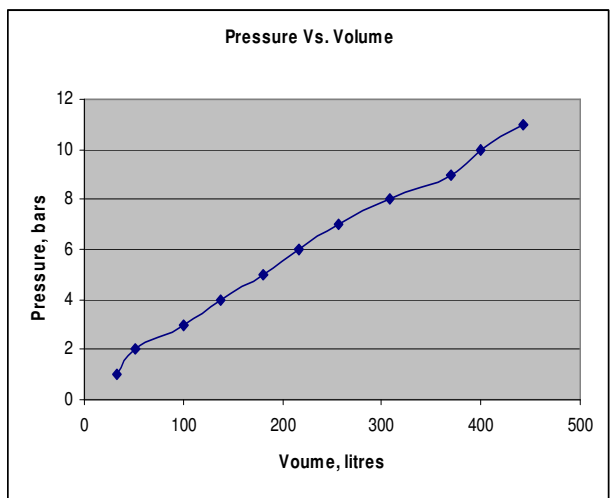

Figure 7 Pressure Volume diagram at near Isothermal Compression

\section{Near Adiabatic condition}

Here compressor was operated continuously. Temperature of the compressed gas was continuously rising, which could be felt from touching the copper tube. Since there were lots of heat loses from different places. The process was not practically adiabatic. Here we could compress only 408 litres of gas at atmospheric pressure into the cylinder.

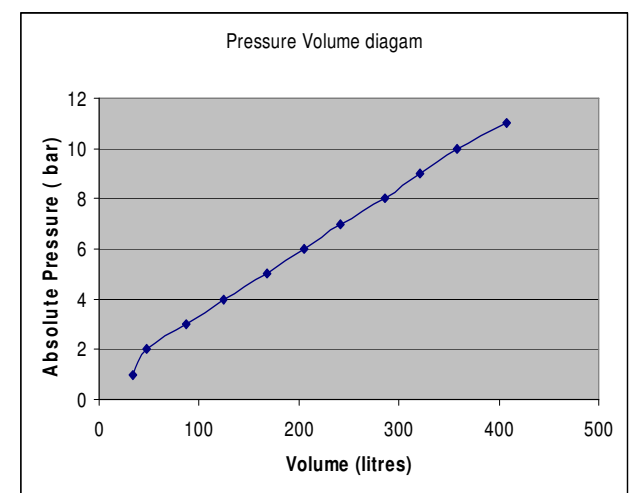

Figure 8 Pressure Volume Diagram for near Adiabatic Condition

Comparing these two results, it is obvious that isothermal condition helps to store more gas on the cylinder. But the time taken for the process will also be high. Hence it will be better, while filling a cylinder, to compress to more pressure than specified and when it cools down its pressure will reach specified and more gas can be stored. 


\section{Stove Compatibility Test:}

First the gas was tested in LPG stove. Sound of gas streaming through the orifice of the stove could be heard, but it couldn't catch fire. Actually LPG stove is designed for LPG, which majorly consists of propane and butane. They are heavier and has energy density higher as compared to that of biogas. Hence, it requires more air to be mixed to make a combustible air-fuel ratio or less flow-rate of the gas. Same amount of air mixed in biogas must have made a very lean mixture which couldn't catch fire.

Then it was tested in Puxin biogas stove. Here, the combustion was smooth. Again a boiling test was conducted to see how much cooking can be done by our cylinder. 175 litres of gas was used to boil 2 litres of water with 15 minutes of simmering time. This is enough to cook rice with 2 litres of water. Using whole of the gas in the cylinder, a typical Nepalese dish can be cooked for a family of 6 people.

\section{CONCLUSIONS}

In the present scenario of energy crisis in Nepal, compressed biogas is a strong viable alternative. There is no doubt that the purified biogas is similar to natural gas, hence it can be used in applications like cooking, generating electricity, stationary motors and vehicles too.

It is proved that biogas can be compressed, stored and made portable. With gross efficiency of $98.71 \%$, biogas was compressed up to an absolute pressure of 11 bars in total of 18-20 minutes in a LPG cylinder. We have established the setup required for the compression and made an earnest effort for the purification also. Hence further study must be continued to develop commercial purification and compression units.

\section{RECOMMENDATIONS:}

- Biogas is no more just the renewable energy source of rural population but it is also an abundant and appropriate source of energy for urban population, having potential to replace fossil fuel. Hence research and proper interest must be given towards advanced use of biogas.

- Compression must be carried out at higher pressure to prove it as an appropriate alternative to petrol and gas vehicles.

- A detailed economic analysis including the cost of biogas plant installation and production of biogas must be carried out with the consideration of water scrubbing system for the removal of $\mathrm{CO}_{2}$ gas.

\section{REFERENCES}

[1] Andrews, Biomethane from Dairy Waste: A Sourcebook for the Production and Use of Renewable Natural Gas in California, Chapter 3, pp 47-69

[2] Karki, Amrit B.; Shrestha, Jagan Nath; Bajgain, Sundar: July 2005, Biogas: as renewable source of energy in Nepal, theory and development

[3] Rai, G.D., 4th edition, 2005, Non Conventional energy Sources, Khanna Publishers.

[4] Nepal Biogas Promotion Group, July 2007, Biogas Sector in Nepal: Highlighting Historical Heights and Present Status

[5] Glub JC, Diaz LF, 1991. Biogas purification process. Biogas and alcohol fuels production, Vol II.: The JP Press Inc.

[6] Hagen M, Polman E. 2001. Adding gas from biomass to the gas grid. Final report submitted to Danish Gas Agency. pp 26-47

[7] Ilyas, Syed Zafar, 2006, A Case Study to Bottle the Biogas in Cylinders as 
Source of Power for Rural Industries Development in Pakistan. World Applied Sciences Journal 1, Volume 2, ISSN 1818-4952, IDOSI Publications pp 27-130

[8] Resnik, K.P., Yeh, J.T. and Pennline, H.W. 2004 Aqua ammonia process for simultaneous removal of $\mathrm{CO} 2, \mathrm{SO} 2$ and NOx, International Journal Environmental Technology and Management, Vol. 4, Nos. 1/2, pp.89104.

[9] S.S. Kapdi, V.K. Vijay, S.K. Rajesh, Rajendra Prasad, Posted 8 May 2003; accepted 23 September 2004, Biogas scrubbing, compression and storage: perspective and prospectus in Indian context
[10] Wise DL, Boca Raton, 1981. Analysis of systems for purification of fuel gas. Fuel gas production from biomass, Volume 2, FL: CRC Press

[11] Nepal Beaurea of Standards and Measurements (NBSM), 1998, Code of practice for L.P. Gas cylinders. Gorkha Prints

\section{Websites}

[12] http://www.cirmac.com

[13] http://www.fao.org 
